\title{
Leveling the playing field through school meals
}

\author{
Aulo GELLI ${ }^{1}$ and Elisabetta AURINO
}

PROGRAM BRIEF|DECEMBER 2019

\author{
${ }^{1}$ International Food Policy Research Institute \\ 2 Imperial College London
}

An analysis of learning outcomes from the evaluation of a national school feeding program in Ghana reveals that disadvantaged students benefited most from free school meals [1]. Overall, students with access to school meals had higher academic and cognitive test scores on average compared with students without access to the program, but the program led to much greater gains for certain disadvantaged groups including girls, students from poor households, ${ }^{1}$ and students from the Northern regions of Ghana. ${ }^{2}$ This evidence suggests that providing free school meals is an effective way to increase opportunities for disadvantaged youth by leveling the playing field through improved educational achievement. However, key structural changes could maximize potential learning impacts resulting from the program. Improvements in program implementation through monitoring the quality and quantity of food served are needed to overcome program implementation challenges identified by the evaluation. Beyond the feeding program itself, investments to improve the quality of education are expected to further improve learning outcomes, especially when school meals incentivize increased school attendance.

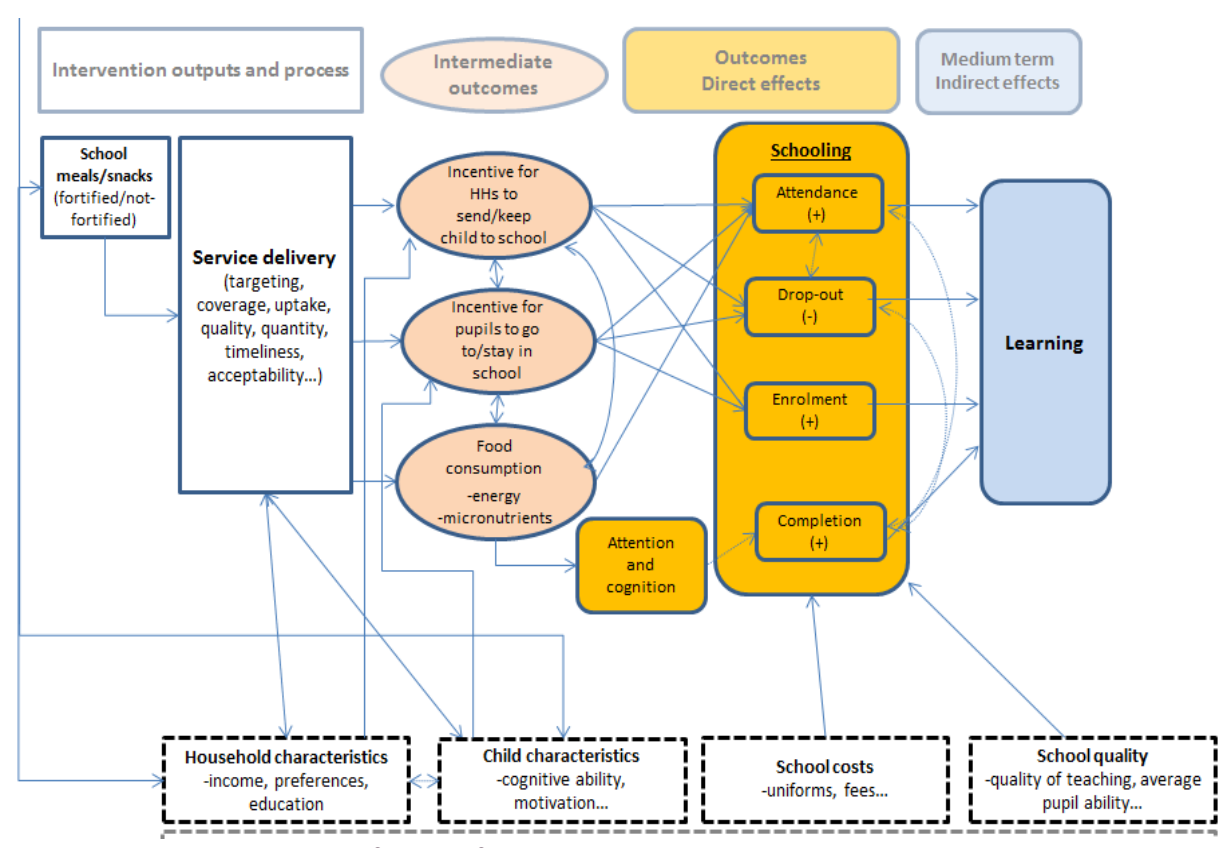

Figure 1: Impact pathway of school feeding program on learning outcomes

*Source: Hunger and learning: Evidence on the costs and effectiveness of providing food through schools in food-insecure areas [2]

\section{EVALUATION OF THE GOVERNMENT OF GHANA'S SCHOOL FEEDING PROGRAM}

The Ghana School Feeding Program (GSFP) reaches two million children across Ghana with a free daily meal. The program was initiated in 2005 as part of an effort to increase school enrollment and is designed to target the poorest districts of Ghana. Although coordinated and funded by the national government, program implementation is decentralized, with District Assemblies contracting local private caterers to procure, prepare, and serve food in public schools. In 2012 the program was retargeted to serve 58 districts experiencing the highest level of poverty and food insecurity.

An evaluation was designed around the scale-up of the GSFP through a partnership between the Government of Ghana, which is the program implementer, and researchers from the University of Ghana, Partnership for Child Development at Imperial College, and IFPRI. The study was designed to measure program effects on education and health at the student level and agriculture at the community level. The analysis in this brief focuses on child-level learning outcomes measured through math, literacy, and cognitive test scores (digit span, standard progressive matrices). Schooling outcomes such as enrollment, attendance, and grade completion are used to test the hypothesized impact pathway of the program on learning outcomes together with child time-use and nutrition (Figure 1).

The evaluation used a cluster randomized controlled trial design. Two comparable schools were selected in each of the 58 implementation districts and randomly assigned to either the school feeding treatment group or the control group. The analysis covers a representative sample of 25 households from each school catchment area with school aged children 5-15 years at baseline. Over 3,500 children were included in the baseline sample. The evaluation covered two full academic years of program implementation (June 2013 to February 2016).

\footnotetext{
${ }^{1}$ Household poverty is calculated from per capita consumption levels below the national consumption poverty line in 2013.

${ }^{2}$ Northern regions include Upper West, Upper East, and Northern region. Southern regions include Western, Central, Greater Accra, Volta, Eastern, Asanti, Brong Ahafo.
} 


\section{LEARNING AND SCHOOLING OUTCOMES}

Students with access to the GSFP had moderately improved learning outcomes compared with students in control schools. A composite test score including math, literacy, and cognitive skills ${ }^{3}$ increased more among students in treatment areas (0.16 SD). ${ }^{4}$ However, further analysis revealed that program effects on learning outcomes were at least twice as great for disadvantaged subgroups of students. Composite test scores were higher for students with access to school meals-among girls ( $0.23 \mathrm{SD}$ ), students from poor households ( $0.33 \mathrm{SD})$, and students in the northern regions of Ghana (0.30 SD).

Schooling outcomes help to explain some of the mechanisms for program effects on learning. Enrollment was an important pathway for effects on learning, but only among the disadvantaged subgroups (girls, poor students, and students in the North) driven by higher enrollment in junior secondary levels since primary enrollment in nearly universal. There were also increases in the time spent in school for the same subgroups, ranging from about 30 additional minutes per day for girls up to 50 additional minutes per day for children from poor households. Improvements in nutrition and time spent in educational activities may also explain the observed program impact on learning outcomes.

\section{MAXIMIZING IMPACTS FOR GREATER EQUITY}

The findings from this analysis suggest that the school meals incentivize enrollment and attendance among marginalized groups, leading to improved learning outcomes. These educational outcomes hold the potential to improve students' future opportunities through better incomes, productivity, and health. Thus, targeting school feeding programs to reach the most vulnerable students can be viewed as both an effective social safety net in the short term and a longer-term investment in human capital, boosting the potential of the most disadvantaged students. The program evaluated in this study targeted schools in the poorest districts of Ghana. Targeting at the student level based on household income could reduce leakage to non-poor students, but this process would require a much higher level of administrative oversight to identify students from eligible households and ensure they receive the meals and would run the risk of enhancing stigmatization of the poor.

A high-profile national program with a large annual budget stands at risk of being used for political leverage. The decentralized delivery of the program is designed to provide income opportunities within local communities but risks wide variation in program implementation and leakage of program funds. The GSFP evaluation specifically identified challenges with consistent training of contracted caters to deliver meals according to the program specifications in addition to late payments to caterers, both of which have implications for meal quality and regularity. Strong social accountability mechanisms are needed to ensure the program is implemented according to design. Service delivery must be regularly monitored by constituencies, with a key role for parent-teacher associations and civil society platforms. Transparent processes, such as district targeting and selection of caterers, can help to lessen politicization of the program.

\footnotetext{
${ }^{3}$ Math, literacy, standardized progressive matrices (SPM) and digit span scores are age-standardized. Composite indices were computed as averages of the standardized scores and then they were standardized to the control group within each round.

${ }^{4}$ Models were estimated through OLS and standard errors were clustered at the community level. For each outcome, the model controls for the baseline value of the outcome, a dichotomous variable related to the randomized assignment to school feeding, and region dummies.
}

\section{REFERENCE}

[1] Aurino, Elisabetta; Gelli, Aulo; Adamba, Clement; Osei-Akoto, Isaac; and Alderman, Harold. 2018. Food for thought? Experimental evidence on the learning impacts of a large-scale school feeding program in Ghana [Supplement]. IFPRI Discussion Paper 1782. Washington, DC: International Food Policy Research Institute (IFPRI). http://ebrary.ifpri.org/cdm/singleitem/collection/p15738coll2/id/133028

[2] Gelli, Aulo. 2012. Hunger and learning : Evidence on the costs and effectiveness of providing food through schools in food-insecure areas. Imperial College, London. https://spiral.imperial.ac.uk/handle/10044/1/12795

\section{Acknowledgements}

The GSFP evaluation was supported by the Partnership for Child Development through grants from the Bill \& Melinda Gates Foundation and Dubai Cares. We acknowledge support from the CGIAR Research Program on Agriculture for Nutrition and Health, led by the International Food Policy Research Institute. Funding for the analysis of learning outcomes from the Ghana School Feeding Program evaluation was received from the Dutch Government through SNV and the Voices for Change Partnership program.

\section{INTERNATIONAL FOOD POLICY RESEARCH INSTITUTE} A world free of hunger and malnutrition

1201 Eye Street, NW, Washington, DC 20005 USA | T. +1-202-862-5600 | F. +1-202-862-5606 | Email: ifpri@cgiar.org | www.ifpri.org | www.ifpri.info 